\title{
Bibliotecas digitales en tiempos de pandemia
}

\author{
Debate coordinado por MIQUEL TÉRMENS GRAELLS \\ Decano de la Facultad de Información y Medios Audiovisuales de la Universitat de Barcelona
}

\section{Resumen}

El debate analiza a través de una serie de preguntas planteadas a cinco profesionales responsables de bibliotecas digitales españolas, los cambios experimentados en su servicio a causa de la pandemia de la Covid19. En las respuestas se constata que mientras que las bibliotecas universitarias estaban bastante preparadas para dar un servicio totalmente en línea, las bibliotecas de otro tipo tuvieron problemas con su infraestructura tecnológica y circuitos de trabajo. Existe un consenso en destacar la importancia de mantener los servicios de soporte al usuario y en aprovechar más las redes sociales como vía de difusión. El aumento de las colecciones y servicios digitales es inevitable, pero se han de encontrar vías para evitar la brecha digital y también para dar sentido a los servicios presenciales.

La pandemia ha puesto de manifiesto fortalezas y aún debilidades en el ámbito digital, pero también que algunos servicios digitales ya tienen veinte años de presencia. En este tiempo ha cambiado de forma radical la oferta de información y cómo ésta es utilizada por los usuarios, por lo que ya es urgente emprender un debate sobre cómo deberán ser las bibliotecas del futuro y que tipo de servicios ofrecerán.

Palabras clave

COVID-19, bibliotecas digitales, servicios, digitalización, preservación digital, información digital

\section{Abstract}

The debate analyses the changes experienced in Spanish digital libraries' service due to the Covid-19 pandemic through a series of questions posed to five professionals responsible for the libraries. The responses show that while university libraries were quite prepared to provide a fully online service, other libraries had problems with their technological infrastructure and work circuits. There is consensus in highlighting the importance of keeping user support services and using social networks as means of dissemination. The rise in digital collections and services is inevitable, but ways to avoid the digital divide and to make sense of face-toface services must be found.

The pandemic has revealed strengths and even weaknesses in the digital sphere, but it has also revealed that some digital services have been around for twenty years. During this time, information offers and how they are used by users have radically changed, so it is now urgent to debate on how the libraries of the future should be like and what kind of services they will offer.

Keywords

COVID-19, digital libraries, services, digitization, digital preservation, digital information

Bajo el principio de que el acceso abierto a los resultados de investigación acelera el avance del conocimiento, todos los contenidos de la edición electrónica de CLIP se distribuyen bajo una licencia de uso y distribución Creative Commons Reconocimiento-NoComercialCompartirlgual 3.0 España (CC BY-NC-SA 3.0 ES). 


\section{Introducción}

La pandemia de la COVID-19 ha golpeado de forma terrible la salud de las personas a nivel mundial y, como si se tratara de un tsunami, sus afectaciones han llegado a incidir en todos los aspectos de nuestras vidas. El teletrabajo, el cierre de los servicios presenciales, las limitaciones a la movilidad personal y la necesidad de establecer una mayor distancia social entre las personas han sido algunos de los fenómenos que han cambiado la vida de las bibliotecas. Por suerte, muchas de ellas han podido continuar con una parte de sus actividades ahora por medios telemáticos. El boom del trabajo en línea y el uso de los medios digitales de comunicación, información y entretenimiento han tenido su paralelismo en el incremento del uso de los servicios digitales de las bibliotecas.

En el Debate de este número de la Revista Clip queremos reflexionar sobre el papel presente y futuro de las bibliotecas digitales. Queremos saber que reflexiones ya se están haciendo desde la profesión sobre la relación que a partir de ahora vamos a tener con las bibliotecas y con las colecciones digitales y que líneas de actuación se vislumbran de cara el futuro. Para ello hemos pedido la colaboración de una serie de profesionales de nuestro país, todos con una larga trayectoria en este campo, y que, desde su visión personal, no de la institución para la que trabajan, nos van a guiar en esta reflexión colectiva.

Advertimos que cada entrevistado ha dado sus respuestas desde posiciones diferentes, algunos han sido muy concretos y en cambio otros han aprovechado para presentar razonamientos más atemporales.

Dadas las limitaciones físicas de la revista, hemos restringido las tipologías de bibliotecas aquí representadas a aquellas en las que las colecciones digitales tienen un mayor peso en la actualidad: biblioteca nacional, biblioteca autonómica, bibliotecas universitarias, consorcios de bibliotecas y bibliotecas especializadas.

\section{Cuestionario}

\section{1. ¿Cómo ha repercutido la pandemia en vuestro servicio de biblioteca digital? (problemas de equipamiento, problemas de personal, saturación de conexiones...)}

\section{Lluís Anglada i de Ferrer (Biblioteca consorciada)}

Mi lugar de trabajo es un consorcio que es proporcionar servicios digitales. Estos servicios en principio están dimensionados correctamente y no ha habido ningún tipo de problema.

\section{Miquel Pastor Tous (Biblioteca universitaria)}

Los equipos y las redes han demostrado que tenían robustez y capacidad suficiente y no han ocasionado problemas. Yo creo que tenemos una infraestructura bastante sólida en las universidades. Para nosotros el impacto fue no tener servicios locales de guía al usuario y tener sólo servicios digitales. Muchos recursos realmente quedaron fuera del alcance de los usuarios y la realidad es que muchos recursos impresos no tienen sustituto viable todavía en medios digitales, especialmente los contenidos locales. En humanidades y ciencias sociales esto se resintió más que en ciencias. 
La verdad es que yo creo que queda lejos todavía la sustitución de los medios impresos.

\section{Gilberto Pedreira Campillo (Biblioteca local)}

Pues la verdad es que caemos en el más profundo caos cuando nos comunican que nos vamos a casa. Cuando la situación se prolongó, la cosa se complicó bastante porque tienes un servicio que es digital, pero que requiere la presencialidad para digitalizar. Felizmente el Ayuntamiento reaccionó y nos montó una VPN y ya por lo menos los bibliotecarios podíamos acceder a los datos de nuestro archivo y a nuestras herramientas fundamentales para trabajar. Días más tarde, se permitió a los trabajadores recoger su propio equipo y llevárselo a casa. Tuvimos que reorganizar todo el servicio, cambiar las formas de trabajo. Y trabajar con la incertidumbre.

Cambiamos a una estrategia de empresa, con un trabajo más intensivo, con gente que estaba digitalizando desde las 9 de la mañana hasta las hasta las 2 de la tarde sin parar. El tipo de fondo también lo variamos, cogiendo un tipo de fondo que sea fácil de manipular y que genere mucho trabajo que luego se pueda procesar por el personal desde su casa.

\section{Mar Pérez Morillo (Biblioteca nacional)}

Lo primero que hicimos fue estar seguros de que la web, el catálogo y los portales digitales, estaban sin problemas y se accedía a ellos sin problemas. Y los informáticos lo que hicieron fue asegurarse de que esto estaba protegido y a salvo.

A partir de ese momento en lo que trabajamos fue en que las personas, los equipos, pudieran seguir trabajando lo más posible en sus tareas habituales, aunque en remoto. Hubo algún período en el que determinadas tareas nos fueron restringidas para asegurarnos de que la red estaba a salvo, de que no haríamos ninguna operación que hiciese caerse los servidores. El servicio estuvo garantizado en todo momento. El personal se puso a trabajar para que pudiéramos subir más fondos a la biblioteca digital. Lo único que no se podía hacer al principio era digitalizar cosas nuevas, porque eso sí requería un trabajo presencial.

Para nosotros, un impacto importante fue recolocar a la gente que tenía principalmente trabajo presencial y buscarles tareas que pudieran ayudar a que el servicio se mantuviera o incluso a que mejorase y creciese.

\section{Eugènia Serra Aranda (Biblioteca autonómica)}

Lo primero que tuvimos que resolver bastante rápidamente fue comprar equipos portátiles, porque no todo el personal disponía en casa de los equipos adecuados para poder seguir haciendo trabajo virtual de la misma manera que lo hacía en la biblioteca. Además, fue necesario adecuarlos como si estuviéramos en nuestro puesto de trabajo.

Luego vimos que el trabajo dedicado a temas digitales ya sea digitalización, servicios que ofrecemos normalmente ya en línea, redes sociales, etc. se debía reforzar e implicar a más personal. Muchos de nosotros tuvimos que aprender el uso de determinadas tecnologías o procedimientos de golpe, sin hacer una formación previa. En esto hubo una respuesta muy positiva de todo el personal, aportando aquellas habilidades que cada uno ya tenía, y hubo 
muchos procesos de mejora en equipo. $Y$ creo que esto ha representado un salto de dos o tres años en el uso de tecnología, un proceso que habríamos hecho más lentamente sin la COVID. Cuando ya nos dejaron abrir la biblioteca, con todas las restricciones y medidas de seguridad, también tuvimos que adaptar la parte de actividad cultural que hace la biblioteca regularmente y que esta también tuvimos que adaptarla en el sentido digital. Así, con la pandemia toda la actividad cultural que ha podido hacer la biblioteca también se ha retransmitido en directo.

\section{2. ¿Habéis activado nuevos servicios digitales durante la pandemia, quizás para suplir algunos presenciales?}

\section{Lluís Anglada i de Ferrer (Biblioteca consorciada)}

Ha habido una movilización internacional a nivel de consorcios de biblioteca para intentar conseguir dos tipos de cosas. Por un lado, más contenidos por el mismo precio. Esto se ha producido quizás más en Estados Unidos que aquí y se ha concretado, por ejemplo, en la relajación de los criterios de acceso a contenidos contratados o de ofrecer contenidos adicionales.

Y, en segundo lugar, ha habido una petición, esto quizá ha sido más europeo, de contención de costes y de precios. Lo más significativo en este sentido es una declaración del JISC inglés (https://www.jisc.ac.uk/) que está pidiendo unas reducciones fuertes de los precios.

\section{Miquel Pastor Tous (Biblioteca universitaria)}

Nos esforzarnos en divulgar mucho más y de forma selectiva a los colectivos que creíamos que les serían útiles los contenidos digitales que ya tenemos. Después también reforzamos mucho el servicio de referencia virtual: pusimos muchas más horas de servicio, pusimos más gente para contestar. Por WhatsApp y por teléfono se podía responder de forma inmediata a problemas, o se podía dar información de recursos, etc. Yo creo que esto ha visibilizado mucho esta función de la biblioteca, que normalmente se desarrollaba en los mostradores.

Aparte de potenciar lo que ya teníamos, tampoco teníamos presupuestos para contratar rápidamente más recursos, pero sí ayudó el hecho de que muchos editores y muchas instituciones abrieran transitoriamente sus recursos. Entonces pudimos avisar a los colectivos que podían ser usuarios de estas colecciones y animarlos a que los usarán rápidamente o que los descargarán porque no sabíamos el tiempo que los tendríamos a disposición.

\section{Gilberto Pedreira Campillo (Biblioteca local)}

Realmente no porqué nuestra biblioteca es digital desde el principio. Pero sí le hemos dado una vuelta a esto. La visita presencial que se hacía a nuestras instalaciones la convertimos en recorridos virtuales y también intentamos proyectar vídeos de un escáner funcionando, vídeos de un paseo por la sala de digitalización. Pensamos que es muy importante que los ciudadanos conozcan el potencial que tiene esto. 


\section{Mar Pérez Morillo (Biblioteca nacional)}

Hemos trabajado mucho en redes sociales, hemos tratado de ser una ventana de la biblioteca en las redes y en la web para que los usuarios que no podían venir presencialmente llegaran a nuestros fondos. Que hubiera material interesante para los niños en casa, para los padres con los niños que no pueden ir al colegio.

Hemos fomentado, por ejemplo, el uso de BNEscolar (https://bnescolar.bne.es/), que es una plataforma de reutilización de contenidos, pero pensada en los colegios y orientada a los colegios, que ha tenido mucho uso por parte de los de los ciudadanos. La jornada de puertas abiertas la hemos tenido que hacer toda virtual e incluso la hemos volcado en Twitter.

También hemos implementado la liberalización del uso de las imágenes de alta calidad, para las que tenías que pagar una tasa si no se trataba de un fin académico o investigador. Con la pandemia era un absurdo seguir manteniendo ese pago por uso y liberalizamos por completo el uso de nuestras imágenes digitales de dominio público. Esto era una reforma pendiente de hacía tiempo, siguiendo las tendencias internacionales. Y la pandemia finalmente la desencadenó.

\section{Eugènia Serra Aranda (Biblioteca autonómica)}

El grueso de la alteración fueron los dos meses y pico que estuvimos todos encerrados en casa. Entonces tuvimos que hacer un poco de maratón para poder ofrecer no tantos servicios diferentes, sino contenidos. Los servicios los manteníamos en línea desde casa. Pero hicimos un esfuerzo para hacer pequeños clips de contenidos de la biblioteca, para pasarlos por las redes sociales y recordar qué se puede encontrar en la biblioteca, a falta de puertas abiertas.

Al cabo de una semana ya teníamos una página web para ofrecer más fácilmente nuestros contenidos digitales: vídeos que teníamos en YouTube, sobre exposiciones, sobre materiales, sobre espacios de la biblioteca, de cómo trabajábamos, etc. Aquí nuestra suerte fue que ya teníamos acceso a mucho material digitalizado.

\section{3. ¿Se ha incrementado el uso de la biblioteca digital? En caso afirmativo, ¿tienes alguna estimación del incremento, en qué tipo de servicios, por parte de qué tipo de usuarios?}

\section{Lluís Anglada i de Ferrer (Biblioteca consorciada)}

Los servicios digitales que ofrece nuestro consorcio CSUC ya tienen un uso muy alto y que está consolidado desde hace bastantes años. Por ello no creo que sean significativos los incrementos que hayamos podido tener durante este periodo de pandemia.

\section{Miquel Pastor Tous (Biblioteca universitaria)}

No ha habido un impacto muy grande del uso de los medios digitales. En buena parte porque sobre todo las revistas electrónicas ya se venían utilizando con mucha intensidad. En abril sí hubo un gran aumento de las descargas, en paralelo a la disponibilidad de nuevos recursos y a la difusión más intensa que hicimos. Pero después las estadísticas más o menos se sitúan en los 
niveles de otros años. De todas maneras, sí que se intensificó el uso de los libros electrónicos. También hemos detectado un incremento de los recursos relacionados con la docencia.

\section{Gilberto Pedreira Campillo (Biblioteca local)}

Las visitas han aumentado más o menos un $30 \%$ y el trabajo en redes sociales se ha visto bastante incrementado, en Twitter y Facebook, por ejemplo. Y en Instagram y YouTube también se ha incrementado, en torno a un 50-55\%.

En YouTube, por ejemplo, hemos centralizado los trabajos de otros servicios que a lo mejor no tenían canal todavía o no tenían la experiencia o la capacidad de difusión que tiene la biblioteca: del Museo de Historia, del Museo de Arte Contemporáneo, etc.

\section{Mar Pérez Morillo (Biblioteca nacional)}

En las semanas siguientes al cierre, las visitas, los accesos y los usuarios se duplicaron. Si comparamos luego el segundo trimestre del año 2020 con respecto al segundo trimestre de 2019, está cerca de duplicarse también el uso de la biblioteca digital. Sabemos que vienen muchas consultas de Iberoamérica y en esta situación más todavía.

También han aumentado las consultas del público general, como reacción a campañas que hemos lanzado en las redes sociales. Twitter es una ventana muy potente y todo lo que hemos incentivado a través de Twitter ha disparado su uso, por ejemplo, las imágenes sobre localidades españolas. Otro incremento del tráfico a la biblioteca digital vino por otra campaña sobre las recetas de cocina durante el confinamiento.

\section{Eugènia Serra Aranda (Biblioteca autonómica)}

El incremento en el uso fue una de las primeras cosas que observamos en nuestros depósitos digitales Memoria Digital de Catalunya (https://mdc.csuc.cat/) y ARCA (https://arca.bnc.cat/). Allí pasamos de 1.900 .000 usos en el 2019 a 2.900 .000 en el 2020. Y esta tendencia se mantiene durante el 2021. Parece que se ha consolidado el hábito de la consulta en línea que han adoptado nuevos usuarios.

4. A la vista de lo que ha ocurrido con esta pandemia con el cierre de los servicios presenciales y la única disponibilidad de los digitales, ¿en qué crees que se deberían reforzar los objetivos, servicios y medios de la biblioteca digital para afrontar mejor el futuro? También, ¿en qué hemos fallado, en que aspectos no estaban suficientemente preparadas las bibliotecas digitales? 


\section{Lluís Anglada i de Ferrer (Biblioteca consorciada)}

Yo creo que las bibliotecas universitarias entraron en su momento en la automatización y ahora estaban preparadas para dar un amplio servicio digital. Pero yo creo que la tecnología sola, sin una necesidad social que la sustente no sirve para nada.

Es muy interesante observar, por ejemplo, el uso o el comportamiento diferenciados entre las revistas y los libros en la universidad. Las revistas, en un proceso muy corto de tiempo, entre 1998 y 2004, pasaron de ser "consumidas" en forma impresa a serlo en forma digital sin que pasara nada; se han cancelado el impreso, y no ha pasado nada. Pero no ha pasado lo mismo con los libros. Seguramente el cambio se realizará dentro de algún tiempo sin que sea fácil saber cuándo será.

Creo que los servicios digitales de las universidades estaban más o menos bien dimensionados y han funcionado bien (por ejemplo, los catálogos colectivos están en línea desde hace tiempo). Otra cosa es la consideración de los servicios presenciales. La respuesta de las bibliotecas a la pandemia ha sido buena, pero ha sido básicamente reactiva y debemos preguntarnos si podía haber sido de otra manera. Las bibliotecas universitarias dicen que al final han tenido que aplicar las normas que les marcaba la universidad, que no ha distinguido entre diferentes actividades y lo ha cerrado todo. He conocido bibliotecarios que han hecho esfuerzos para adaptar la biblioteca a las normas que creían correctas y no les han dejado abrir por motivos seguridad. Creo que el resultado ha sido un nivel de servicio muy por debajo del deseable. Si nosotros, los bibliotecarios, estamos diciendo que las bibliotecas son indispensables, tenemos la paradoja de que durante mucho tiempo han prestado servicios bastante por debajo de su potencial.

\section{Miquel Pastor Tous (Biblioteca universitaria)}

Nosotros ya éramos conscientes antes de la pandemia de que teníamos pocos libros electrónicos. Había universidades o comunidades autónomas que habían financiado la adquisición de grandes paquetes de libros electrónicos, pero en nuestro caso no era así. Esto ha sido mitigado por la apertura de las colecciones, pero quedó en evidencia que, si no se hubiera hecho esto, nos hubieran faltado muchos libros electrónicos y mucha bibliografía básica para los alumnos.

Después también los recursos de tipo más local para la investigación en ciencias humanas y ciencias sociales: mucho material de investigación en historia o en filología... Se ha visto que disponemos de los grandes paquetes de revistas electrónicas y también podremos disponer en el futuro del libro electrónico de carácter académico, pero en los recursos locales en red aún hay mucho por hacer.

\section{Gilberto Pedreira Campillo (Biblioteca local)}

En una biblioteca digital como la mía, local, que atiende a la ciudad de Madrid, que recoge todo tipo de documentación, es importante incrementar las acciones de difusión, eso para nosotros es fundamental. Y seguir creciendo, seguir innovando. Pues ahora estamos trabajando en 3D, porqué detrás de una reconstrucción 3D podemos ofrecer toda la documentación que nos ha servido para levantar esa reconstrucción. 
Nosotros también somos necesarios para la propia administración de la ciudad, para el archivo de la Villa. Esto sí nos lo planteamos para la pandemia: vamos a intentar digitalizar lo máximo posible para poder facilitar trabajos o consultas que se hacen diariamente en los padrones de habitantes, por ejemplo. Aunque no es precisamente la documentación más bonita del mundo, es muy importante y consultada. También que la gente pueda seguir pidiendo una licencia de obras y que la gente pueda seguir haciendo una consulta de donde vivía su abuelo en el año tal, etcétera. En nuestros planes de digitalización ahora esta documentación es prioritaria. Y apostar cada vez más por la preservación de estos medios digitales es fundamental. Y más con los panoramas apocalípticos que hemos vivido.

\section{Mar Pérez Morillo (Biblioteca nacional)}

No es lo mismo una estrategia digital en una biblioteca local o que en una biblioteca autonómica que en una biblioteca nacional. Todos más o menos teníamos dibujado un camino de estrategia digital y esta situación no ha hecho más que abundar en la necesidad de profundizar ese plan. Nosotros ya teníamos la idea de digitalizar más, de preservar digitalmente más, de dar un mejor acceso a nuestras colecciones y de fomentar la reutilización de nuestros datos y de nuestros fondos. Y lo que ha hecho esta situación no ha sido más que subrayarlo y en eso hemos trabajado en remoto.

¿Qué es lo que nos falta? Pues la infraestructura que lo sustenta se ha encontrado en una situación crítica de mucha demanda desde dentro y desde fuera de la biblioteca. Los trabajadores de la biblioteca han demandado mucho más de nuestra infraestructura tecnológica para trabajar en remoto. Pero hemos sufrido limitaciones para realizar tareas muy intensivas a nivel informático para evitar el peligro de que el sistema se bloqueara

De esto hemos aprendido mucho. Ahora tenemos todos acceso en remoto, se ha fomentado el teletrabajo, se ha permitido compatibilizar la vida personal y laboral. Esto ha puesto sobre la mesa un camino digital que ya intuíamos que no tenía vuelta atrás y que había que profundizar y ahora se ha asentado como algo crítico y básico para las bibliotecas.

\section{Eugènia Serra Aranda (Biblioteca autonómica)}

Yo soy una convencida de que todo el contenido que podamos poner en abierto en digital lo hemos de poner. Lo que ocurre es que tenemos diversas cosas que no ayudan. Una es que las bibliotecas no tenemos en general suficientes recursos no solo para digitalizar, que es una parte, sino para publicar de una manera coherente. Más allá del tema de la digitalización, nos encontramos que son muy escasos los contenidos con derechos en dominio público, porqué las fechas de los derechos de autor son muy amplias. Creo que hay que hacer una reflexión y buscar un nuevo modelo que nos permita poner más contenidos en la red. Es verdad que para todo lo que se está publicando más recientemente ya existen plataformas de préstamo de libros, etcétera, que suplen en parte esto. Pero entre los años veinte del siglo pasado hasta los ochenta, tenemos un agujero de cincuenta o sesenta años que hemos de resolver porque esas obras ni están a la venta (y por tanto no se consultan en las plataformas) ni las podemos digitalizar porque tienen derechos de autor vigentes. 


\title{
5. Desde el punto de vista de una visión estratégica a largo plazo, ¿qué reflexiones te lleva a hacer la pandemia respecto al papel o la configuración de las bibliotecas digitales?
}

\author{
Lluís Anglada i de Ferrer (Biblioteca consorciada)
}

No se puede desgajar la biblioteca digital del conjunto de la biblioteca. Aunque en algunos ámbitos bibliotecarios se llama biblioteca digital a aquella parte digital de la biblioteca, en estos momentos nuestro entorno es un entorno mixto, híbrido claramente, en el que una parte sostiene a la otra.

Ahora estamos en el año 2021 y no el año 2000. Hay nuevas realidades que han emergido. Creo que hay cuatro que quizás se han manifestado lentamente a lo largo de estos años. La primera es que ha cambiado radicalmente el lugar donde se produce el descubrimiento. En estos momentos el ojeo no se produce en los estantes y muy difícilmente en los catálogos, se produce en Google, con lo cual instrumentos tradicionales, como es el catálogo, entran en cuestión.

En segundo lugar, ha entrado en juego la abundancia de la información. Hoy nos falta tiempo y abunda la información. Esto nos produce el tercer fenómeno, lo que en inglés le dicen el "good enough"; esto es suficientemente bueno para la gran mayoría de usuarios. $Y$ finalmente yo creo que el cuarto elemento que existe es una cosa también que se formuló en inglés en su momento que dice "information wants to be free", en el sentido de fluidez.

Estoy hablando de información y de usuarios. Si un usuario ahora no descubre las cosas en el mismo lugar, si quiere la información libre, si prima el good enough y si la información es abundante, nuestro entorno ya no es la biblioteca en la que tú y yo estudiábamos.

La biblioteca no deja de tener sentido, pero debe recrear su sentido. Este no es un tema propio de la pandemia, sino que es un tema que viene formándose desde hace tiempo. Yo creo que estamos en un momento de redefinición profunda.

\section{Miquel Pastor Tous (Biblioteca universitaria)}

Se tiene que avanzar mucho en el tema de ciencia abierta, es importantísimo trabajar y avanzar todo lo que podamos en esto. También a nivel de las administraciones, más a nivel autonómico, local, en las universidades, tenemos que hacer proyectos de digitalización de los recursos más próximos y crear bibliotecas digitales, archivos digitales, etcétera. $Y$ esto necesita una colaboración entre administraciones y una programación a medio y largo plazo para priorizar. Nosotros estamos trabajando en ello con archivos municipales y con la biblioteca digital de las Islas Baleares (http://ibdigital.uib.es/). Pero da la sensación de que vas un poco a salto de mata, que depende del interés de un alcalde, del interés de un director general en un momento dado, pero que falta un poco este plan estratégico de digitalización que priorice las actuaciones. En el caso de la adquisición de recursos electrónicos, es necesario un cambio estratégico del sistema de financiación de las adquisiciones y se ha de romperse la dinámica de los presupuestos atomizados y crear un fondo potente y centralizado que pueda acometer una política de colecciones digitales coherente. 


\section{Gilberto Pedreira Campillo (Biblioteca local)}

Pienso que en el futuro puede ocurrir otra vez lo mismo [la pandemia] y que nosotros hemos adoptado una estrategia que creo será magnífica. Vamos a tratar de ser útiles más allá de lo que hace tiempo se entendía por biblioteca digital. Es decir, tenemos documentos históricos muy bonitos, como manuscritos del siglo XVII, la mayor parte de ellos en latín y que no son muy consultados por los investigadores. Pues volvemos al origen de nuestra biblioteca, a dar respuestas a la gente común que nos preguntaba cosas sobre una foto determinada, sobre el primer ascensor que se inventó, etc. Vamos a volver un poco a ese germen, vamos a ser útiles más allá de si ese documento es bonito o no.

En el pasado demasiadas bibliotecas hemos pensado principalmente en el usuario especializado y no en la ciudadanía general. Ahora vamos a hacer cosas que sabemos que con pandemia o sin pandemia van a ser rentables, rentables para una ciudad normal, para el usuario.

\section{Mar Pérez Morillo (Biblioteca nacional)}

Ahora nuestra actuación toma forma con el plan estratégico que acaba de aprobar la biblioteca, en el que una parte muy grande tiene que ver con la estrategia digital. Pero en realidad es que desde hace tiempo queremos no hablar de digital y físico, porque cada vez más es un todo. Por ejemplo, el depósito legal empieza a ser un depósito de lo físico y de lo que está en línea. Y la gestión también tiene que ser conjunta. Tenemos que ser eficientes porque todo requiere mucho esfuerzo en equipos, en recursos.

Una cosa importante que la pandemia ha sacado también a la luz es que la digitalización parece que estaba un poco de capa caída. Estábamos pensando en preservar, en reutilizar, en dar unos accesos más versátiles, más usables, etc. Pero si no tenemos digitalizado mucho material, el servicio que damos a posteriori no tiene sobre qué darse; la digitalización es la base de todo y tiene un coste. Son cosas en las que cuesta hoy hablar, de qué quieres invertir mucho dinero, porque son menos sexis. Es decir, uno quiere hablar de proyectos, de datos abiertos, de explotación y de tratar de ir un paso más allá, pero si yo tengo digitalizado sólo un tercio de mi colección, lo que puedo construir sobre eso es sólo un tercio de lo que puedo dar.

Nosotros estamos viendo que, por ejemplo, con cargo a los planes de recuperación de la Unión Europea, tenemos que hacer un gran esfuerzo para digitalizar más. De todas maneras, también es verdad que tú debes demostrar la importancia de la digitalización, tienes que demostrar que eso sirve para hacer otras cosas, como proyectos de crowdsourcing, proyectos de aplicación a las escuelas, de explotación de grandes conjuntos de datos; se ve que todo eso se puede explotar y reutilizar. Y ello da sentido a la digitalización.

\section{Eugènia Serra Aranda (Biblioteca autonómica)}

Si hablamos estratégicamente a largo plazo, no sólo de los contenidos, nos hemos de fijar también muy bien en los perfiles laborales que tenemos en las bibliotecas, ahora mayoritariamente formados por bibliotecarios y similares. Estamos en un mundo en que todo cambia y esto también ha de cambiar. Tenemos que ir hacia unos equipos mucho más mixtos, donde haya perfiles orientados a la comunicación virtual y digital, periodistas digitales y abogados para todo el tema de derechos de autor. 


\section{6. ¿Consideras que el ritmo actual de inversión en digitalización, en preservación digital y, en general, en infraestructura digital es suficiente?}

\section{Lluís Anglada i de Ferrer (Biblioteca consorciada)}

El problema no es la inversión. El tema es que estamos digitalizando mal y sin coordinación, con digitalizaciones duplicadas o que no se encuentran donde deberían estar.

¿Lo que nos falta son recursos?, no. En la universidad española hay repositorios digitales y muchos de ellos no están más llenos no porque falte infraestructura si no por qué no hay cola para incorporar más materiales y no hay ayudas para esto. Antes de la crisis del 2009 hubo planes de digitalización y ayudas para digitalizar que han desaparecido. Dejando de lado iniciativas loables como las de la Biblioteca Nacional, no hay planes españoles, catalanes, regionales, de digitalización. Y no hay una buena visión de lo que es el mundo digital. El mundo digital será un ecosistema de servidores interoperables y esto se tiene que construir con generosidad.

Lo que nos falta no son inversiones, lo que nos falta son ideas, objetivos, planes y proyectos conjuntos.

\section{Miquel Pastor Tous (Biblioteca universitaria)}

La inversión se ha de aumentar, porqué buena parte de esta inversión se conseguía de proyectos o de convenios, pero no había una programación. Yo creo que ahora es muy importante consolidar la programación en temas como la preservación digital. Tenemos que vender que no nos basta con digitalizar, sino que todo eso tiene que preservarse a largo plazo. Tiene que estar muy seguro, muy disponible en cualquier momento.

Creo que la pandemia va a ser un impulso para las inversiones digitales, porque se ha demostrado que estas inversiones han dado mucho rendimiento.

\section{Gilberto Pedreira Campillo (Biblioteca local)}

En educación y en sanidad la inversión siempre es poca. Siempre tenemos la capacidad de seguir creciendo en nuestras ideas y nuestros planteamientos. En digitalización hemos invertido más o menos y hemos creído que digitalizando lo vamos a conservar toda la vida, pero en preservación todavía no se está invirtiendo lo suficiente.

Yo veía fotos de Madrid, de ciudades de España completamente vacías y la visión es completamente apocalíptica. ¿Y qué pasa si en vez de ser una pandemia es una catástrofe nuclear? Entonces, pues, ¿cómo no va a ser poco lo que invirtamos en preservación? Es poco todo lo que se haga.

\section{Mar Pérez Morillo (Biblioteca nacional)}

Este ritmo ha de cambiar, pero no sé cómo. Por ejemplo, nuestra biblioteca digital, se ha formado por dos grandes impulsos principales uno, el patrocinio de Telefónica y otro el convenio con 
red.es; una vez acabados estos, la biblioteca no ha tenido dinero para invertir con esos mismos niveles. Por eso ahora estamos concentrando nuestros esfuerzos en que el plan de recuperación nos proporcione dinero y que podamos aplicar una buena parte a digitalizar. Tenemos que aprovechar esta ocasión para dar un fuerte impulso a la digitalización y a la preservación digital.

\section{Eugènia Serra Aranda (Biblioteca autonómica)}

Evidentemente no. Con los años vamos mejorando, pero no solo debe mejorar la infraestructura de las bibliotecas, sino toda la infraestructura de telecomunicaciones en las calles y para acceder las personas desde su casa. Ha de haber un trabajo importante a nivel de país y de Estado para garantizar que si nosotros ponemos contenidos estos contenidos luego puedan ser utilizados de una manera sencilla en las bibliotecas y en las ciudades. Si vamos a una sociedad digital lo ha de ser para todos. En cuanto a la preservación digital, evidentemente aún nos falta muchísimo. No la tenemos conceptualizada y no tenemos, incluso los profesionales, interiorizado que la preservación digital va de la mano de la digitalización, tanto si nos gusta como si no, porque es la manera de ahorrar recursos en el futuro y de garantizar la pervivencia de los contenidos. Por poner un ejemplo: que cada vez que una institución digitaliza, no digitaliza pensando en preservación digital, y esto es algo que hemos de introducir claramente en el ciclo de vida de una digitalización y todavía no es así. Por lo tanto, el ritmo actual no es suficiente, pero tampoco la conceptualización de cómo es un proceso de digitalización.

7. ¿Qué opinión tienes ante la acusación de que el auge de lo digital (incluyendo las bibliotecas digitales), no hace más que agrandar la brecha digital de las personas desfavorecidas, cosa que va en contra de la misión social de las bibliotecas?

\section{Lluís Anglada i de Ferrer (Biblioteca consorciada)}

Ahora voy a dar una respuesta vulgar: digamos que esto de la tecnología no es buena ni mala, sino depende para qué se utiliza.

La biblioteca es un gran corrector. El gran inventor de la biblioteca moderna es la sociedad de los Estados Unidos, a finales del siglo XIX. Es una sociedad llena de inmigrantes, que pasa del mundo agrícola al mundo industrial, del campo a la ciudad. $Y$ estos cambios brutales necesitan amortiguadores, como las escuelas, las asociaciones, como lo fueron los ateneos y lo son las bibliotecas. Yo diría que en este sentido las bibliotecas tienen más capacidad para contribuir a la igualación.

También es verdad que quien tiene que corregir las tendencias no son las bibliotecas, sino la sociedad. Nosotros como bibliotecarios hoy hacemos esta función, es verdad, pero si la sociedad, no quiere, no somos nosotros quienes tenemos que regenerar la sociedad.

\section{Miquel Pastor Tous (Biblioteca universitaria)}

Al final la brecha digital es una brecha económica y una brecha social. Se debe tener en cuenta que a la gente desfavorecida, económica o socialmente, se la tiene que ayudar. 
En la universidad se ha sido muy sensible a esto. Nosotros pusimos todos los recursos de la videoteca, los portátiles y todos los elementos que teníamos dentro de las bibliotecas para que salieran precisamente para apoyar a los alumnos o al personal que no contaba con medios propios. Pero esto tiene que continuar en el futuro. O sea que la gente que no tiene medios por falta de capacidad económica para acceder a los medios digitales se le tienen que proporcionar de una manera solidaria.

Se ha visto que la biblioteca es un muy buen gestor también de todos estos elementos. Porque estamos acostumbrados a prestar las cosas, a gestionarlas y a tenerlas controladas.

\section{Gilberto Pedreira Campillo (Biblioteca local)}

Esto camina hacia lo digital, es así. Sí que es verdad que no debemos dejar a nadie atrás. Tenemos que poner los medios para evitar esta brecha digital. Creo que las administraciones, y todos en general, nos tenemos que poner las pilas en que esta gente no se quede atrás, no sin dejar de avanzar. $Y$ las bibliotecas tiene un papel esencial. Lo dice la IFLA.

Creo que las infraestructuras han de estar a disposición del ciudadano. Quiero decir que, si no tienes un ordenador o no tienes una ADSL, alguien te tiene que poner ADSL, es un derecho, igual que necesitas el agua para beber y necesitas la luz para vivir. Las comunicaciones las necesitas para vivir ahora mismo: la tendrás para vivir, para trabajar, para seguir a tu hijo en clase, etcétera.

\section{Mar Pérez Morillo (Biblioteca nacional)}

La parte, digamos, social que tiene las bibliotecas en cuanto a proximidad, en cuanto a un sitio al que el ciudadano recurre, eso digitalmente no tiene sustitución. Esa función social, sobre todo de las bibliotecas de barrio, o públicas y municipales, eso no tiene sustitución por la biblioteca digital. Pero también podemos actuar al revés de lo que parece. Efectivamente, hay gente que no tiene dispositivos móviles, pero hoy casi cualquiera, tiene un teléfono móvil. Y sabemos que muchas familias que han tenido muchas dificultades para seguir el colegio de sus hijos durante los meses de confinamiento, a veces lo han hecho a través de un móvil. Entonces, si podemos acercar el conocimiento, las colecciones, los datos, los actos culturales de una biblioteca a través de un dispositivo móvil, con podcasts, con vídeo, con una biblioteca digital accesible, y podemos tener más colecciones disponibles a través de dispositivos móviles, yo creo que no se acentúa la brecha digital. Al revés, superamos distancias geográficas, que, en un pueblo perdido de la España vaciada se pueda tener acceso a todas las colecciones digitales de las grandes bibliotecas del mundo a través de una tableta, de un portátil o de un móvil.

Estamos también mirando, pues, que los actos culturales, las conferencias, las exposiciones puedan ser virtuales, se retransmitan en streaming, que ya lo hacíamos en parte, pero que además podamos hacer webinars, que la gente participe. La pandemia nos ha abierto otro foco, la necesidad de llegar a otros públicos que están lejos. Yo creo que el que las bibliotecas sean más digitales no acentúa la brecha, sino que creo que reduce las desigualdades en el acceso a la información. 


\section{Eugènia Serra Aranda (Biblioteca autonómica)}

Este es un debate importante que tiene que ver en nosotros, el colectivo bibliotecario. Cuando creamos las bibliotecas pensamos que con ellas precisamente lo que estamos haciendo es democratizar, porque físicamente se puede ir a la biblioteca y entonces allá te podrás conectar a donde quieras. Esto está muy bien, pero si vamos a hacia una sociedad digital, esto es insuficiente. $Y$ es insuficiente porque luego en su casa, determinadas clases sociales no van a tener acceso a lo que tiene el resto. Entonces hay que poner los medios para que esto no pase, y esta ha de ser una acción colectiva, como cuando se proporcionaron tablets a los niños que no podían ir físicamente a clase. Acciones de este tipo son las que se han de hacer, asegurar que aquellos que están más desfavorecidos tengan al menos el mínimo de infraestructura en su casa para poder acceder. $Y$ para esto están las administraciones públicas, para romper la brecha digital.

\section{8. ¿Crees que el auge de lo digital que ahora hemos vivido tendrá repercusiones en los servicios bibliotecarios? ¿En otras palabras, se incrementará el peso de lo digital dentro del conjunto de servicios e inversiones bibliotecarias?}

\section{Lluís Anglada i de Ferrer (Biblioteca consorciada)}

Creo que existen cambios profundos en los hábitos de los lectores, pero son previos a la pandemia. Por ejemplo, el descubrimiento de materiales se hace marginalmente en los catálogos y la abundancia de información confunde a la gente. Tenemos que preguntarnos qué debemos hacer. En este sentido, por mucho que una biblioteca compre todos los libros digitales existentes en el mundo no por ello va a cambiar los comportamientos lectores de los universitarios. Pero en cambio, quizás si la biblioteca asume que lo que tiene que hacer o lo que puede hacer es fomentar más cursos de alfabetización digital, de buen uso, de lo que sea, pues esto quizá sea el cambio que necesitamos.

\section{Miquel Pastor Tous (Biblioteca universitaria)}

Estas inversiones extraordinarias en equipos portátiles, en equipos que se puedan prestar tanto dentro como fuera del campus, creo que van a quedarse.

Por otro lado, hasta ahora hemos trabajado mucho en repositorios de investigación y en repositorios de producción científica y en revistas electrónicas, básicamente para apoyar la investigación. Pero con esta crisis se ha visto que para los recursos docentes no tenemos una infraestructura y que los recursos docentes los tienen los profesores en sus ordenadores o están colgados en un aula digital no se sabe muy bien cómo. Se tiene que avanzar en la docencia abierta y en recursos para la educación online, para la que se necesitan materiales y estrategias nuevas. Debemos sistematizar lo que ya tenemos y que sea reutilizable para toda la comunidad. 


\section{Gilberto Pedreira Campillo (Biblioteca local)}

Los servicios digitales que hemos empezado a ofrecer obtienen una respuesta del público, lógicamente, y se van a seguir haciendo y se van a seguir desarrollando. Y así debe ser. Pero sí también es verdad que el contacto con el libro de toda la vida es importante. Yo creo que se debe seguir yendo a las bibliotecas, que tienen que seguir abiertas, ofreciendo los servicios presenciales. Hay que ver a la gente y también hay que entrar en contacto con las fuentes. Todas las bibliotecas hacen un papel esencial a pie de obra, esencial a pie de calle y eso no se puede perder. Pero eso no quita que el peso de lo digital también aumente cada vez más.

\section{Mar Pérez Morillo (Biblioteca nacional)}

Cuando hablamos de los planes de recuperación de la Unión Europea, hay dos grandes líneas que tienen que ver que se Ilaman Green and Digital. O sea, las dos grandes líneas están en cuanto al cambio climático y el medio ambiente y en cuanto a la digitalización. Hemos visto que esto de cerrar los países, de cerrar a la gente en sus casas, nos deja la salida digital, porqué si no estamos incomunicados. Se ha demostrado que esta vía digital hay que reforzarla, ampliarla y permitirla a mucha más gente.

\section{Eugènia Serra Aranda (Biblioteca autonómica)}

Creo que debe continuar el incremento de lo digital. Pero sin olvidar que todas las bibliotecas pueden tener un papel socializador, porque no podemos acabar todos "solo en casa", comunicándonos "solo" desde casa. Creo que se ha de llegar a un término medio, presencial y digital, porque poner en contacto a las personas también es importante para que las sociedades avancen. Con las videoconferencias hemos comprobado que se pierde una parte de la comunicación, como el lenguaje corporal y la manera de relacionarte es diferente. Si superamos la brecha digital, también debemos tratar de no perder otro tipo de actividades que sean más de carácter presencial.

9. ¿Tienes alguna recomendación a hacer a nuestros compañeros o a los estamentos de decisión? (Es necesario ir hacia... Se debe incrementar... Se debe cambiar... Se ha de acelerar...)

\section{Lluís Anglada i de Ferrer (Biblioteca consorciada)}

Yo creo que tendría que haber un modo de actuar más proactivo. Las bibliotecas han tenido una gran reacción, somos muy profesionales y yo no estoy cuestionando a nivel personal la actitud de la gente, pero lo que las bibliotecas básicamente han hecho es cerrar, en cambio el super donde yo compro no ha cerrado cuando ha habido pandemia.

No podemos ir diciendo que las bibliotecas son indispensables y un motor de la economía. Pero después resulta que cuando queremos activar la economía, primamos una cosa y no las bibliotecas, que han quedado cerradas. Esto nos tendría que hacer reflexionar sobre cuál es 
nuestro papel. Yo creo que nuestro papel es muy importante a medio largo plazo, nunca a corto plazo. $Y$ este es el tema, creo que como profesión nos equivocamos: el corto plazo, el cortoplacismo, el incremento de números. ¡No! Tenemos que defender las bibliotecas desde un punto de vista muy ideológico. Tenemos que decir a la sociedad que los espacios para socializarse, para gestionar información, son buenos para crecer personalmente, son buenos para las personas y son buenos para la sociedad a medio y largo plazo.

\section{Miquel Pastor Tous (Biblioteca universitaria)}

No se debe olvidar el papel fundamental de los espacios bibliotecarios. Tenemos que potenciar lo digital, pero los espacios de las bibliotecas son unos espacios privilegiados para la lectura, para el estudio, para los trabajos colectivos, para socializar la cultura y la información.

Que la digitalización llegue a los recursos locales, en culturas y lenguas minoritarias, porque esto es otra brecha digital. Tenemos muchos recursos digitales, pero la gran mayoría de los recursos de calidad son en inglés o en las lenguas grandes a nivel mundial. Yo creo que aquí las universidades y las bibliotecas de las comunidades autónomas pueden hacer un gran trabajo.

\section{Gilberto Pedreira Campillo (Biblioteca local)}

Como recomendación profesional recordar aquello de siempre de optimizar la colección según las necesidades del usuario.

Y sobre todo no perder de vista la preservación. Vuelvo a la imagen del panorama apocalíptico, que hemos visto que puede ser muy grave si perdemos un montón de información. Imaginemos que a nivel científico se pierdan los datos que se han recuperado de todas las investigaciones para hacer vacunas, sobre la pandemia; y mañana o dentro de 20 años caemos en otra situación similar. Pues desgraciadamente tendremos que rehacer un montón de trabajo. La preservación puede parecer cara, aunque yo creo que no y, en todo caso, la rentabilidad a medio o a largo plazo es tanta que lo justifica todo.

\section{Mar Pérez Morillo (Biblioteca nacional)}

Yo creo que con todo lo que ha pasado no hace falta recomendarle a nadie nada, porque está clarísimo el camino que nos marca. En la estrategia digital hemos de reforzar cuatro pilares: empezando por la digitalización, siguiendo por la preservación digital a largo plazo, mejorando el acceso de los ciudadanos (no sólo a las colecciones, sino a todo lo que hacemos, como la actividad cultural) y fomentamos y creamos más herramientas para poder explotar y reutilizar los datos y las colecciones que tenemos digitales. Si no reforzamos estas cuatro patas, no cumpliremos la misión que tienen las bibliotecas, que es atender a los ciudadanos y facilitar el acceso a la información.

\section{Eugènia Serra Aranda (Biblioteca autonómica)}

Desde hace ya unos cuantos años que a mis compañeros en la biblioteca les digo una cosa: que hemos de acostumbrarnos a vivir en la eterna incertidumbre porque la sociedad es muy 
cambiante. El consumo cultural es cambiante. Los usuarios son cambiantes. Las herramientas digitales ya no digamos lo a cambiantes que son. Por tanto, nos hemos de mover en una continua incertidumbre que no nos ha de crear ningún agobio. Simplemente saber que nuestra profesión y el desarrollo de nuestra actividad diaria va a estar siempre en adaptación. Esto no es negativo, simplemente que hemos cambiado de modelo: hace 30 años todo estaba como mucho más estabilizado y ahora este modelo ha cambiado. Pues estupendo.

A los a los dirigentes o a quien pueda oírlo y quiera oírlo. Creo que nos hace falta hacer una reflexión a fondo de lo que puede pasar en 20030 años y la hemos de hacer hoy, no dentro de 10 o de 15. Saber cómo van a ser nuestros usuarios dentro de 20030 años, los usuarios que principalmente son nacidos ya nativos digitales. Con este conocimiento habríamos de sentarnos y definir una estrategia colectiva clara a 20030 años. Si cada vez se incrementa más el uso digital y bajan los usos presenciales, es evidente que incluso físicamente los espacios deben cambiar. Una cosa que está cada vez más clara es que los usuarios ahora, y aún más en pocos años, ya no siguen aquel modelo de usuario que "yo te pido y tú me das", sino que quieren trabajar conjuntamente. es una cosa mucho más interactiva. El consumo cultural ha cambiado, los hábitos también. Entonces, esta reflexión de aquí a 30 años creo que se debería impulsar y esto a lo mejor nos permitiría saber exactamente dónde hemos de invertir, porque habremos de invertir no sólo en infraestructuras, sino en la propia formación que hemos de tener los profesionales, sobre todo en esta mirada a largo plazo acerca de qué hemos de hacer con los espacios físicos y qué nuevos servicios hemos de empezar a diseñar.

\section{Conclusiones}

Ya hemos explicado en la introducción que el debate ha tenido dos niveles de reflexión, el más próximo provocado por el impacto de la pandemia, y el más alejado en el que se discute sobre el presente y el futuro de las colecciones digitales dentro de las bibliotecas.

Hemos visto que el aumento de la demanda de información digital no ha sido un problema para aquellas bibliotecas ya más avanzadas en ofrecer este tipo de información, como son las bibliotecas universitarias y las especializadas como Memoria de Madrid. En cambio, han sufrido aquellas bibliotecas patrimoniales en las que el núcleo de su colección solo puede ser consultado de forma presencial, como la BNE y la Biblioteca de Catalunya. En todos los casos se ha remarcado que la actual oferta de contenidos digitales es parcial y no atiende ni a todas las necesidades informativas ni a todas las tipologías de usuarios; en las actuales colecciones digitales, sean de digitalización propia o de contratación externa, existe un evidente sesgo hacia los materiales orientados a la investigación o los materiales "preciosos" (fondo antiguo... ), que no se corresponde necesariamente con los usuarios mayoritarios a los cuales ha de atender cada biblioteca.

El estado de alarma puso de manifiesto que a pesar de que la mayoría de las bibliotecas cuentan con un elevado nivel de informatización, éste dista mucho de estar optimizado para permitir el teletrabajo de la mayoría del personal.

En cuanto a los servicios, los entrevistados han coincidido en destacar dos aspectos. El primero es la importancia de contar con servicios de comunicación directa con los usuarios, sea para informarles de nuevos materiales o sea para dar soporte a sus preguntas y problemas; aquí han destacado el poder de las redes sociales junto a otros como la atención telefónica, el WhatsApp 
o el chat. En segundo lugar han destacado la necesidad de mantener el contacto personal, la presencialidad, sin la cual las bibliotecas pierden buena parte de sus poderes.

En último lugar han coincidido en que estamos en una sociedad plenamente digital, sin vuelta atrás. En este contexto la brecha digital existe, pero las bibliotecas digitales, de forma presencial y también digital, son herramientas esenciales para su reducción.

En el ambiente de las respuestas ha planeado un cierto aire de fin de ciclo, el que las bibliotecas españolas empezaron en los años noventa con la informatización y luego a incorporación de contenidos digitales. Ya no es posible ver lo físico y lo digital como ámbitos separados, ni vivir de la inercia del pasado. El mayor problema actual de los usuarios ya no es la falta de información, que antes ofrecían en exclusiva las bibliotecas, si no su exceso, que pueden obtener fácilmente en internet, por su cuenta. ¿Cuál ha de ser la función futura de estos espacios bibliotecarios que tanto se han añorado durante la pandemia? ¿Cómo han de estar configuradas unas colecciones digitales, en cuanto a funcionalidades y a composición, que básicamente han de competir con otros muchos contenidos disponibles en la red? Estas son preguntas y respuestas que quedan para nuevos debates.

\section{Entrevistados}

Lluís Anglada i de Ferrer

Director del Área de Ciencia Abierta del Consorci de Serveis Universitaris de Catalunya (CSUC), Barcelona

Miquel Pastor Tous

Director de la biblioteca de la Universitat de les Illes Balears, Palma de Mallorca

Gilberto Pedreira Campillo

Director de la biblioteca digital Memoria de Madrid, del Ayuntamiento de Madrid

Mar Pérez Morillo

Directora de la División de Procesos y Servicios Digitales de la Biblioteca Nacional de España, Madrid

Eugènia Serra Aranda

Directora de la Biblioteca de Catalunya, Barcelona 


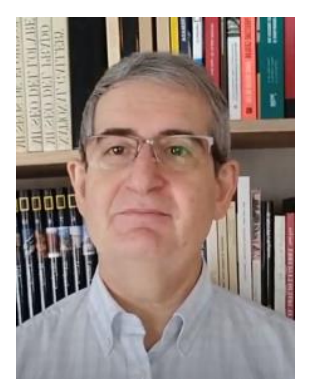

\section{MIQUEL TÉRMENS GRAELLS}

Es doctor en Documentación, licenciado en Historia y diplomado en biblioteconomía y documentación. Actualmente es Decano de la Facultad de Información y Medios Audiovisuales de la Universitat de Barcelona Está especializado en preservación digital, en gestión de proyectos de digitalización y en gestión técnica de bibliotecas digitales. También colabora con empresas y otras instituciones como consultor en estos ámbitos.

termens@ub.edu

@mtermens 